\title{
AVALIAÇÃO DE REDAÇÕES DE VESTIBULAR: DA TEORIA À PRÁTICA ${ }^{12}$
}

\section{ASSESSMENT OF UNIVERSITY ENTRY WRITING EXAMS: FROM THEORY TO PRACTICE}

\section{Marcela Franco Fossey*}

\section{RESUMO}

Este trabalho apresenta uma reflexão a respeito da avaliação de testes de escrita. Embora esta pesquisa, de modo mais amplo, esteja situada na interface entre estudos do texto e do discurso e pesquisas na área de avaliação, o foco é, neste momento, na análise textual e discursiva que subjaz à prática avaliativa de textos produzidos em condições de vestibular. Analiso o conceito lacuna, que na grade de correção utilizada atualmente pela Fundação para o Vestibular da Unesp (Vunesp) operacionaliza a avaliação da qualidade dos argumentos apresentados nas redações, mobilizando especialmente o conceito de ethos discursivo (Maingueneau, 2005, 2010). O corpus selecionado é composto por redações produzidas em um vestibular de alta demanda. Com isso, quero demonstrar como o conceito de lacuna funciona e como ele é um exemplo de parâmetro de avaliação que atende aos critérios de aplicabilidade e robustez teórica, uma demanda que defino como central para a elaboração de critérios de avaliação de testes de escrita como redações de vestibular.

Palavras-chave: dissertações de vestibular; avaliação de escrita; ethos discursivo.

\section{ABSTRACT}

This paper presents a reflection about the assessment of large scale writing tests. Although this research, in a broader perspective, is situated in the interface between text and discourse theories and educational assessment studies, this work is mainly focused on the textual and discursive analysis undertaken during the assessment of university entry writing exams. The concept of "gap" is analyzed, which operationalises the evaluation of the argumentative quality of essays in the scoring guide used by the Fundação para o Vestibular da Unesp (Vunesp). The concept of discursive ethos (Maingueneau, 2005, 2010) is the main theoretical notion mobilized for the analyses. The corpus comprises a set of essays produced by occasion of a highly competitive university entry exam. The objective is to demonstrate how the concept of gap works and how it is an example of evaluation parameter that responds to both criteria of applicability and theoretical robustness, a central demand for the elaboration of scoring tools for assessment of large scale writing tests.

Keywords: university entry writing exams; writing assessment; discursive ethos.

* Universidade Estadual de Campinas, Campinas (SP), Brasil.. marcela.ff@gmail.com

1. Este trabalho apresenta alguns resultados de uma pesquisa de pós-doutoramento em andamento desde setembro de 2016, no âmbito do Programa de Pós-Graduação em Linguística Aplicada do Instituto de Estudos da Linguagem da Unicamp, sob supervisão da Profa. Dra. Raquel Salek Fiad. Bolsista PNPD/Capes.

2. Uma versão resumida deste trabalho foi apresentada no $18^{\circ}$ AILA World Congress of Applied Linguistics. 


\section{UMA LONGA INTRODUÇÃO (OU AS QUESTÕES QUE SE COLOCAM NO HORI- ZONTE DESTA PESQUISA)}

As provas de redação foram reintroduzidas nos concursos vestibulares nacionais com o Decreto no. 79.298 em 1977, depois de quase 10 anos de exames unificados compostos exclusivamente de testes de múltipla escolha. As provas discursivas haviam sido excluídas dos exames vestibulares no final da década de 1960, com a promulgação da Lei no. 5.540, de 1968 - a Reforma Universitária -, que unificou os concursos vestibulares e definiu uma série de mudanças nos conteúdos cobrados e em seu formato. Dentre essas mudanças, estava a definição do uso exclusivo dos testes de múltipla escolha em suas provas.

O retorno de testes de escrita aos vestibulares foi marcado por uma série de reflexões sobre as consequências da sua adoção nos moldes então propostos (na forma de uma prova de redação que solicitaria um texto argumentativo). Uma delas era relativa à possibilidade de se obter resultados fidedignos em avaliações dessa natureza (cf. Vianna, 1984). Além dessa questão, em alguma medida de ordem técnica, a escrita dos vestibulandos tornou-se, também, objeto de estudo linguístico, já que se tratava de um objeto novo, pouco conhecido e pouco estudado, e que ocupou papel importante nas discussões de então sobre o ensino de língua materna e, mais especificamente, sobre o sentido de "saber escrever" no contexto de ensino e aprendizagem de leitura e escrita ${ }^{3}$.

Em geral, a redação tem sido analisada, no Brasil, ao longo desses 40 anos em que está presente nos vestibulares, com o objetivo de descrever, a partir de diferentes perspectivas teóricas, os fenômenos linguísticos e textuais observados nos textos dos vestibulandos ${ }^{4}$. Mais recentemente, muitas pesquisas têm abordado, também, o efeito retroativo das provas de redação a partir da análise do impacto desse tipo de teste nas decisões de ensino de escrita em sala de aula ${ }^{5}$.

3. Pietri (2007) discute como a redação de vestibular surge como objeto de interesse para a linguística a partir de uma ruptura com os estudos tradicionais da língua, de orientação normativa. O corpus analisado pelo autor é composto pelos primeiros artigos publicados, no final da década de 1970, que divulgam pesquisas sobre redação de vestibular. Sua conclusão é a de que a relação polêmica entre conhecimentos da linguística e uma perspectiva fundamentada nos estudos tradicionais da linguagem (que tomam como modelo de análise a gramática normativa) permeia o nascimento deste objeto. Para Pietri, a publicação dessas pesquisas - em três números dos Cadernos de Pesquisa (16 e 19, de 1976, e 23, de 1977), da Fundação Carlos Chagas - marca a definição desse gênero de texto escolar como objeto de análise para os estudos linguísticos.

4. A título de exemplo, cito os trabalhos de Lemos, 1977; Osakabe, 1977; Pécora, 1986; Costa Val, 1991; Fiad, 2000; Maciel, 2010; Brito, 2011. A título de exemplo, cito os trabalhos de Scaramucci, 2005; Silva \& Lino de Araújo, 2009; Vicentini, 2015.

5. A título de exemplo, cito os trabalhos de Scaramucci, 2005; Silva \& Lino de Araújo, 2009; Vicentini, 2015. 
No entanto, a avaliação dessas redações é um aspecto pouco explorado nas pesquisas nacionais. Enquanto ferramenta psicométrica, provas de redação são testes de desempenho, isto é, são exames que necessitam de julgamento de avaliadores especializados. Tipicamente, a avaliação de testes de desempenho envolve vários examinadores independentes, como é o caso das provas de redação de vestibulares, que contam com centenas de participantes, eventualmente, milhares (como é o caso, por exemplo, do Enem, cuja edição de 2016 teve mais de 10 mil avaliadores envolvidos). Nesse contexto de avaliação, a consistência das pontuações atribuídas pelos diferentes avaliadores é um grande desafio, mas considerada condição indispensável para garantir a precisão dos resultados.

Portanto, a definição de parâmetros claros e funcionais para que todos os avaliadores possam atribuir pontuações da forma mais similar possível é essencial para que os resultados sejam considerados consistentes. No caso específico de avaliação de escrita, há uma diversidade de metodologias, mas, em geral, pode-se classificá-las em duas grandes categorias: a holística e a analítica. Na holística, o texto é avaliado de forma global, e os diversos elementos presentes em um texto (por exemplo, aspectos relacionados à sintaxe, adequação e variedade vocabular, elementos de coesão, adequação do tema, etc.) não são avaliados separadamente. $\mathrm{O}$ resultado é uma pontuação única e que se refere à totalidade do texto. Na avaliação analítica, por sua vez, o texto é analisado de forma compartimentada, considerandose uma diversidade de rubricas, isto é, de critérios associados àqueles elementos presentes no texto, e que constituem (ou garantem) a textualidade. O resultado final é a somatória das notas atribuídas em cada uma das rubricas definidas. No Brasil, a avaliação analítica é empregada por boa parte dos grandes vestibulares e pelo Enem, que eventualmente tornam públicos os critérios utilizados. Esses critérios são, em geral, organizados na forma de uma grade de correção com descritores de desempenho associados a uma determinada pontuação. Essa grade de correção define não só diferentes aspectos textuais - formais e de conteúdo - que devem ser avaliados, como também prevê uma variedade de realizações textuais para cada um dos critérios, que são associados a um desempenho e, assim, a uma nota. A definição de parâmetros que orientam o olhar do avaliador para diferentes elementos do texto é uma das principais estratégias para tornar a avaliação menos subjetiva e menos orientada por critérios pessoais de qualidade ${ }^{6}$.

6. A questão dos erros de medida em testes psicométricos é tema caro aos estudos da área, que se dedica a definir estratégias que possibilitem medir de forma confiável processos mentais - como personalidade, aptidão ou proficiência em escrita, por exemplo. Neste contexto de pesquisas, especialmente aplicado na área de Psicologia e Educação, muitos estudos têm se voltado para a questão da interferência dos avaliadores nos resultados de testes de desempenho. Para uma visão 
A definição desses parâmetros não é uma tarefa simples: por um lado, é necessário mobilizar teorias do texto e do discurso para definir critérios de linguagem adequados para analisar e categorizar uma grande quantidade de textos que se apresentam de maneiras muito diversificadas; por outro, é preciso que tais critérios sejam aplicáveis neste contexto específico de análise textual, que tem como uma de suas características principais a participação de um grande conjunto de avaliadores independentes. Ou seja, a análise textual que é realizada em situação real de atribuição de notas em redações de vestibular (ou de qualquer texto produzido em avaliações externas de larga escala) é muito específica, na medida em que o desempenho dos candidatos é avaliado por um grupo heterogêneo de avaliadores e não por um avaliador único, como ocorre em sala de aula. Assim, esses parâmetros devem possibilitar, ao máximo, a homogeneidade no olhar de todos, de modo que desempenhos semelhantes recebam pontuações semelhantes.

Nesse contexto, parâmetros estatísticos, de base psicométrica, têm como função indicar, por exemplo, os níveis de confiabilidade dos resultados e são utilizados como baliza para a definição dos critérios textuais de análise. Isto é, o bom funcionamento de um critério é avaliado observando-se, por exemplo, os percentuais de concordância entre todos os avaliadores envolvidos no processo. De fato, a concordância entre avaliadores tem sido considerada, nos estudos em medidas educacionais, um dos mais relevantes critérios de qualidade em avaliações de escrita e é, certamente, em um contexto de avaliação de escrita psicometricamente orientado (como é o caso de boa parte dos concursos vestibulares que utilizam dupla correção às cegas), o principal indicador de que os resultados são consistentes.

No entanto, não é livre de críticas essa associação direta entre confiabilidade (dos resultados do exame) e concordância (entre avaliadores), especialmente quando o que se quer medir é algo como a escrita. Pesquisadores envolvidos com o ensino de escrita (e com questões de texto e de discurso de maneira mais ampla) têm questionado a confiabilidade, operacionalizada pela medição da consistência entre observações independentes a respeito do desempenho que se quer avaliar, como indicador por si só da qualidade dos resultados de um teste. Em especial quando a ideia de justiça, outro importante parâmetro de qualidade, se apresenta como resultado natural e garantido da confiabilidade. A esse respeito, Huot (1996) afirma que

é lógico pensar, portanto, que os mesmos procedimentos que garantem consistência garantem também a justiça. Porém, não é o caso. Devemos entender que em avaliação de escrita a confiabilidade entre avaliadores independentes significa consistência entre avaliadores

mais ampla e profunda do tema, especificamente em testes de linguagem, cf. Toffoli, 2015 e Wind \& Peterson, 2017. 
e nada além disso. [...] A consistência é apenas um aspecto da justiça. [...] Procedimentos que envolvam os professores no desenvolvimento e na discussão e que reflitam claramente parâmetros locais previamente negociados e definidos é o que poderá prover julgamentos justos e responsáveis da produção escrita de estudantes. Traduzir confiabilidade em justiça não é apenas inadequado, mas perigoso, porque isso iguala consistência estatística a valores sobre a natureza do julgamento que está sendo feito 7 . (HUOT, 1996, p. 557)

\section{O que Huot parece indicar é sua preocupação com o fato de que a qualidade} dos resultados de um teste de escrita tem sido profundamente definida em termos estatísticos, enquanto que as estratégias que possibilitam gerar esses resultados são colocadas em segundo plano. $\mathrm{Ou}$, ainda pior, que as estratégias de análise textual são definidas de modo a garantir sua consistência estatística, ignorando as práticas anteriores de sala de aula ou a natureza nem sempre tão previsível da escrita ${ }^{8}$.

7. Original em inglês: "Logically, then, the same procedures which ensure consistency should also provide fairness. However, this is not the case. We should understand that in writing assessment interrater reliability means consistency among raters and nothing else. [...] Consistency is only one aspect of fairness. [...] Procedures that involve teachers in development and discussion and reflect clearly defined and negotiated local standards should provide for fair and responsible judgements of students writing. Translating reliability into fairness is not only inaccurate, it is dangerous because it equates statistical consistency with value about the nature of the judgement being made".

8. Outra questão que está diretamente associada aos testes de escrita nos moldes dos vestibulares nacionais é relativa à padronização que caracteriza tais provas, na medida em que, de uma perspectiva psicométrica, quanto mais padronizado é um teste, maior o potencial de se obter resultados confiáveis. O que implica, portanto, que testes não padronizados não possibilitam gerar resultados confiáveis. A esse respeito, Moss (1994, p. 6) afirma: "dada a crescente quantidade de evidências a respeito do impacto de testes de alta relevância na prática educacional [...], privilegiar a padronização é problemático. [...] Há certas atividades intelectuais que avaliações padronizadas não podem nem documentar nem promover; elas incluem encorajar os alunos a encontrar suas próprias razões para ler e escrever, encorajar professores a tomar decisões bem fundamentadas relativas ao ensino e que sejam consistentes com as necessidades individuais dos alunos, e encorajar alunos e professores a colaborarem entre si para o desenvolvimento de critérios e padrões para avaliar o próprio trabalho". [original em inglês: "Given the growing body of evidence about the impact of high-stakes assessment on educational practice [...], this privileging of standardization is problematic. [...]. There are certain intellectual activities that standardized assessment can neither document nor promote; these include encouraging students to find their own purposes for reading and writing, encouraging teachers to make informed instructional decisions consistent with the needs of individual students, and encouraging students and teachers to collaborate in developing criteria and standards to evaluate their work".]. Essa é uma questão que está além do escopo definido para o presente trabalho (é, definitivamente, uma pedra no sapato das práticas de avaliação), mas que sem dúvida alguma é de extrema relevância e está sempre no horizonte de uma discussão sobre avaliação educacional: em que medida testes padronizados são justos e éticos? Eles não reforçam a exclusão de certos grupos que, historicamente, já são excluídos? Eles de fato conseguem apreender e medir habilidades subjacentes à escrita? E, principalmente, quais as consequências que esses testes, cada vez mais presentes nas sociedades ocidentais, trazem para o ensino (não só de escrita, mas de maneira geral)? A literatura concentra um grande número de trabalhos que desenvolvem esses questionamentos. Para uma visão mais profunda do tema, ver o trabalho já citado de Moss (1994) e o volume 9 (1) da revista The Journal of Writing Assessment, cuja temática foi exatamente a ética em testes de escrita. 
Além disso, a necessidade de adequação estatística pode gerar inadequações em relação ao construto que se propõe avaliar: ao se buscar meios de garantir a concordância entre avaliadores, é possível que haja, por exemplo, simplificações extremas na caracterização dos traços de textualidade que se quer avaliar. A esse respeito, esse mesmo autor constrói um exemplo hipotético (e extremo) bastante elucidativo:

Por exemplo, eu poderia decidir medir a escrita de um aluno a partir da contagem do número de palavras presentes na dissertação (na realidade, até um computador poderia fazer isso). Esse método poderia alcançar uma concordância entre avaliadores perfeita, já que possivelmente dois juízes independentes contariam o mesmo número de palavras. Ainda que confiável, dificilmente poderíamos considerar meu método como uma forma justa de avaliar a escrita do aluno9. (HUOT, 1996, p.557)

Esse exemplo evidencia a crítica de Huot ao fato de o como da avaliação ocupar, via de regra, um papel secundário nas pesquisas (psicometricamente orientadas) em avaliação de escrita, especialmente o aspecto relativo ao que vou chamar de conteúdo especializado: anteriormente, apontei que um dos principais desafios na definição de critérios de avaliação de redações de vestibular é possibilitar atender tanto às demandas estatísticas quanto às demandas linguísticas. Isto é, não basta definir critérios que sejam absolutamente adequados em termos de teorias do texto e do discurso se esses critérios não permitem que os avaliadores possam aplicá-los de forma homogênea, gerando resultados confiáveis em termos psicométricos. Por outro lado, não basta atender aos parâmetros estatísticos, sem que haja robustez teórica de cunho linguístico/textual nos critérios que orientam a atribuição de notas por parte dos avaliadores. A afirmação pode parecer um tanto óbvia, mas o fato é que são raras as pesquisas nacionais que propõem essa discussão.

Considerando, assim, este cenário permeado de desafios, em que se faz necessária a transformação de teorias linguísticas complexas em critérios de avaliação aplicáveis em uma situação de correção efetiva e que atendam às demandas psicométricas de concordância entre avaliadores independentes - na medida em que os vestibulares são testes psicometricamente orientados -, neste trabalho proponho uma reflexão sobre a avaliação de textos dessa natureza, como são as redações dos vestibulares nacionais. Para tanto, exploro a noção de lacuna, aplicada para a avaliação da qualidade dos argumentos nos processos de correção das dissertações

9. Original em inglês: "For example, I could decide to measure student writing by counting the number of words in each essay (in fact, a computer could count the words). This method could achieve perfect interrater reliability, since it is possible that two independent judges would count the same number of words for each paper. While reliable, we could hardly consider my method to be a fair evaluation of student writing". 
produzidas nos vestibulares realizados pela Fundação para o Vestibular da Unesp (Fundação Vunesp). Conforme buscarei mostrar, avaliar uma redação de vestibular considerando as lacunas argumentativas nela presentes (ou ausentes) é um exemplo concreto de operacionalização de conceitos oriundos das teorias do texto e do discurso para fins de avaliação textual em larga escala.

Embora esta pesquisa, de modo mais amplo, esteja situada na interface entre estudos do texto e do discurso e pesquisas na área de avaliação, o foco é, neste momento, na análise textual e discursiva que subjaz à prática avaliativa de textos produzidos em condições de vestibular. A proposta de análise que apresento é, em boa medida, um retorno a um trabalho realizado há alguns anos, quando, enquanto Técnica em Avaliação Educacional da Fundação Vunesp, estava envolvida com a definição de novos parâmetros de avaliação das redações de seus concursos e vestibulares. Naquele momento, em que a instituição fazia a transição de uma grade holística para uma grade analítica, era preciso definir critérios que atendessem às duas demandas já especificadas: aplicabilidade e consistência teórica. Nesse contexto, a proposta de análise de lacunas como estratégia de análise da qualidade argumentativa surgiu a partir da constatação de que, frequentemente, e em maior ou menor grau, muitas redações apresentavam afirmações categóricas que surgiam como verdades inquestionáveis, cabais, claras, evidentes e simplificadas, compreensíveis para todos. Característica facilmente observável por qualquer leitor devidamente treinado, a ideia de lacuna surgiu, assim, como uma alternativa produtiva para a avaliação do traço argumentativo dos textos. O presente artigo é, neste sentido, um trabalho de explicitação de conceitos teóricos que de uma forma não tão sistematizada guiaram as decisões quando da proposta da grade. Mas para além da discussão a respeito dessa decisão específica, o objetivo deste artigo é, também, tecer considerações sobre os desafios implicados na avaliação de escrita em vestibulares enquanto testes padronizados de escrita.

Antes de prosseguir, é importante esclarecer que essa proposta de análise se aplica à avaliação de dissertações argumentativas, que assumirei como um gênero tipicamente escolar e que, quando produzidas em situação de vestibular, apresentam especificidades, que serão consideradas ao longo das análises e discussões.

\section{VISÃO GERAL DA GRADE DE CORREÇÃO UTILIZADA PELA VUNESP}

As provas de redação dos vestibulares realizados pela Vunesp solicitam, em grande parte dos casos, a elaboração de dissertações argumentativas. Mais especificamente, a maioria das propostas apresentam aos candidatos questões 
polêmicas e dicotomizadas, e o candidato deve, sempre, defender um dos pontos de vista possíveis, que costumam ser claramente apresentados tanto pelos textos de apoio quanto pela frase temática.

A grade de correção utilizada para correção dessas provas é formada por três critérios: (A) Tema; (B) Estrutura (gênero/tipo de texto e coerência) e (C) Expressão (modalidade e coesão). A pontuação total prevista é de 11 pontos: 0 a $3 \mathrm{em}(\mathrm{A}) ; 0$ a $4 \mathrm{em}$ (B), 1 a 4 em (C). Cada uma das gradações especificadas pelos conceitos, em cada um dos critérios, é acompanhada de um descritor, que apresenta as características gerais dos textos que devem ser classificados com cada uma das notas possíveis.

A análise das lacunas é prevista pelo critério (B) Estrutura (gênero/tipo de texto e coerência), que avalia o domínio que o candidato tem do gênero dissertação argumentativa, com foco especial no modo como os argumentos são apresentados no texto $^{10}$.

\section{A NOÇÃO DE LACUNA E SUA RELAÇÃO COM A ARGUMENTAÇÃO}

Avaliar uma dissertação argumentativa implica avaliar como é construída a argumentação que lhe dá corpo. A organização composicional prototípica das dissertações é conter introdução, desenvolvimento e conclusão, partes que se interligam tendo em vista o propósito argumentativo que caracteriza o gênero, em que estratégias textuais e linguísticas são mobilizadas de modo a demonstrar que o ponto de vista defendido é válido e o melhor possível. Trata-se de um texto que deve possibilitar a identificação clara do posicionamento assumido pelo enunciador, além de apresentar argumentos que busquem a adesão do leitor à tese defendida. Neste sentido, a organização estrutural esperada é que o texto apresente na introdução a questão a ser analisada, eventualmente com a indicação do ponto de vista a ser defendido; argumente de modo a sustentar seu posicionamento ao longo do desenvolvimento e que a conclusão seja claramente um término decorrente da argumentação apresentada.

Assim, olhar como os mecanismos argumentativos são ativados nas redações se mostra como uma estratégia necessária para o reconhecimento do domínio que os candidatos têm da escrita que será avaliada nesse contexto. Neste sentido, analisar como a argumentação é construída vai ao encontro da função avaliativa e classificatória das provas de redação de vestibular.

10. Para uma apresentação detalhada de cada um dos critérios, c.f. Fossey (org.) (2017). 
Os modos de se olhar para a construção da argumentação são muitos e variados. É possível, por exemplo, analisar a argumentação com foco nas relações lógicas que as provas de argumentação devem sustentar, como propõe Osakabe (1977). Ou como propõe Esvael (2011), com foco nas adjetivações, compreendidas como movimentos argumentativos que incidem na construção de pontos de vista. Ou analisando a orientação argumentativa dos enunciados a partir dos conectores, mobilizando a teoria dos topoi argumentativos, de Ducrot (1989). Esses modos de se explicar o fenômeno argumentativo, embora obviamente válidos do ponto de vista teórico, impõem uma dificuldade operacional, no sentido de que em uma situação real de avaliação de textos em larga escala, não há tempo para a análise que essas teorias demandam. Elas também não favorecem uma gradação que possibilite identificar uma realização ideal do fenômeno (e outras menos ideais). Essas questões se colocam exatamente pela função da análise textual que a avaliação de redações de vestibular, em última instância, implica: uma classificação. Assim, não basta identificar um determinado fenômeno, mas é preciso atribuir uma gradação a respeito de sua qualidade, dentro de uma escala pré-definida. Por isso, a proposta para compor a grade da Vunesp foi por analisar as lacunas como indício da qualidade dos argumentos, que é definida de um modo bastante específico: pela demonstração da sua pertinência no projeto argumentativo do texto.

Essa proposta toma como base a persuasão enquanto traço central da argumentação, tal como proposto na retórica aristotélica. No entanto, assumimos que a persuasão não ocorre somente por meio das técnicas argumentativas clássicas (as formas de inferência e de raciocínio, os tipos de argumentos mobilizados, etc. $\left.{ }^{11}\right)$, mas na totalidade do texto. Neste sentido, propor que se avalie a qualidade argumentativa dos textos a partir da análise das lacunas implica assumir que todo enunciado é argumentativo, isto é, que a dissertação é um todo argumentativo.

Essa prerrogativa é especialmente produtiva se consideramos as dissertações produzidas em vestibulares naquilo que elas têm de mais específico. Como já indicado, as lacunas são caracterizadas como "falta de desenvolvimento dos argumentos" que, vale repetir, não são apenas os argumentos previstos, estudados, descritos nas teorias clássicas da argumentação; neste contexto de avaliação, consideramse como argumentos todo movimento do enunciador/candidato (ou locutor 1, na nomenclatura ducrotiana) no sentido de persuadir seu co-enunciador/interlocutor, persuasão que se dá em dois planos distintos, mas profundamente interdependentes: no plano textual-discursivo, busca-se persuadir um auditório universal a respeito do ponto de vista assumido; no plano empírico (do mundo extralinguístico), busca-se

11.Para uma visão ampla e detalhada sobre argumentação, cf. Fiorin, 2015. 
persuadir a banca avaliadora de que ali, escrevendo a redação, há um candidato bem-preparado e que domina a escrita de dissertações. Essa relação entre mundo extralinguístico e mundo textual-discursivo tem implicações específicas para a produção e avaliação desses textos. Ao colocar em cena tanto um candidato quanto um enunciador - aspecto que será discutido adiante - busca-se persuadir em dois níveis complementares, mas distintos. Assim, a ideia de lacuna se constrói sobre uma noção de argumentação como estratégia de persuasão.

Enquanto ferramenta que possibilita avaliar e classificar, a noção de lacuna oferece a vantagem, por assim dizer, de buscar características facilmente identificáveis nos textos, o que garante, em boa medida, sua aplicabilidade em uma situação real de avaliação, em que muitos textos devem ser lidos em um curto período de tempo, e por um grupo heterogêneo de avaliadores. Além disso, ela possibilita uma gradação bastante objetiva: há textos com muitas lacunas, com lacunas pontuais e sem lacunas. Porém, apesar da simplicidade prática que a identificação de lacunas supõe (possível de ser realizada com uma leitura rápida e técnica, como é a feita em avaliação de redações de vestibular), a noção se apresenta, como buscarei mostrar com as análises e discussões, como a ponta do iceberg: identificar a ausência ou presença de lacunas em uma dissertação como um traço indicativo de sua qualidade argumentativa se sustenta em uma enorme "parte submersa", isto é, em um aparato teórico robusto que análises mais detalhadas comprovam.

É importante destacar que a presença ou ausência de lacunas na argumentação não é o único critério observado relativo à construção do texto: além do atendimento ao tema, e aspectos relativos à coesão e à norma culta (que são avaliados nos critérios A e $C$, respectivamente), o próprio critério $B$ observa outros elementos do texto, a saber: a progressão temática, a organização dos parágrafos e a presença ou ausência de contradições internas.

Considerando, portanto, o objetivo deste trabalho e os limites de espaço, serão apresentadas apenas as análises de redações que foram avaliadas como acima da média: como se verá, as lacunas operam, nessas redações, como um diferenciador relevante entre textos bons e aqueles que recebem a pontuação máxima.

Esses textos foram produzidos por candidatos do vestibular misto 2017 da Universidade Federal de São Paulo (Unifesp). Trata-se de um processo seletivo para os cursos de Ciências Biológicas, Engenharia Química, Fonoaudiologia e Medicina.

As provas de redação dos vestibulares realizados pela Vunesp são, em geral, compostas de textos de apoio, que trazem informações que visam contextualizar a questão abordada pelo tema, orientações gerais sobre a tarefa a ser realizada (o gênero e o registro a ser empregado na escrita) e uma frase temática, que define 
o escopo da discussão a ser desenvolvida pelo candidato. No caso da prova que foi o ponto de partida para a produção dos textos que serão analisados a seguir, foi solicitada a escrita de uma dissertação, empregando a norma-padrão da língua portuguesa, sobre o seguinte tema: O voto nulo é um ato político eficaz?

\section{ANÁLISES ${ }^{12}$}

Os exemplos são compostos por duas redações que foram avaliadas com as notas 3 e 4 no critério $B$, sendo que a pontuação nos outros dois critérios foi a máxima, ou seja, é exatamente a qualidade da argumentação que os diferencia. $\mathrm{O}$ texto que recebe a pontuação 3 no critério $B$ pode ter lacunas pontuais, conforme o descritor da grade: "a maioria dos argumentos é desenvolvida, mas alguns não são: há lacunas pontuais". Já para receber a pontuação máxima, os argumentos devem ser bons, isto é, desenvolvidos. Para esse nível, a grade prevê "bom desenvolvimento dos argumentos: ainda que haja rara lacuna ou quebra, os argumentos são justificados/ desenvolvidos de modo a convergir para o ponto de vista defendido".

A opção por analisar textos com essas características justifica-se por eles possibilitarem observar a presença ou ausência de lacunas de maneira mais pura, por assim dizer. Isto é, como poderá ser observado nas análises que se seguem, não há interferência de escolhas lexicais imprecisas nem de construções frasais inadequadas, que prejudiquem o processo de compreensão do texto e, eventualmente, se confundam com ou mesmo potencializem as lacunas argumentativas da redação. Além disso, foram escolhidos textos que atendem plenamente aos outros aspectos de textualidade avaliados, a saber, o de progressão temática e de não contradição.

O exemplo 1 apresenta uma redação na íntegra, cuja pontuação no critério B foi 3 .

12. Os dados analisados - notas finais e máscaras das redações - foram gentilmente fornecidos pela equipe de TI da Fundação Vunesp para fins de pesquisa. Compõem esse conjunto de dados os textos e as respectivas notas de 230 redações. Os exemplos que são apresentados no presente artigo fazem parte de um conjunto em que 14 redações foram analisadas. Devido à limitação de espaço, foram selecionados apenas dois exemplos prototípicos dos traços textuais e discursivos que permitem caracteriza as lacunas. Os textos foram transcritos tal como constam nos originais. 


\section{Exemplo 1}

$01 \mathrm{O}$ voto nulo consiste em uma forma de recusa do cidadão em apoiar algum candidato em 02 determinada disputa eleitoral. É um tema de grande relevância na atualidade, visto que nas 03 recentes eleições municipais houve um número expressivo de abstenções. Em metrópoles 04 como São Paulo e Belo Horizonte, tal índice superou 20\%. Apesar de grande parte dos eleitores 05 considerar a anulação um ato político, é necessário ressaltar que a referida prática não apresenta 06 eficácia real.

07 Inicialmente, cumpre observar que, ao contrário da crença popular, a expressividade de votos 08 nulos não invalida o processo eleitoral. Ou seja, algum candidato será, invariavelmente, eleito. 09 Tendo em vista que o cidadão que anula o voto com base em uma motivação política é, em 10 geral, um eleitor com razoável senso crítico, pode-se argumentar que as abstenções em larga 11 escala facilitam a vitória de candidatos menos honestos. Isso ocorre pois os votos que poderiam 12 ser destinados a adversários mais responsáveis são desperdiçados por meio da anulação.

13 Outro aspecto que atesta o caráter inócuo dos votos nulos é o fato de eles, apesar de sinalizarem 14 uma insatisfação social em relação à conjuntura política, não produzirem um incômodo efetivo 15 sobre os governantes. Ressalta-se que tal descontentamento, por se expressar de maneira pouco 16 frutífera, pode ser interpretada pelos políticos como um sinal de apatia da sociedade. Por 17 conseguinte, reduz-se a pressão social que tais representantes sofrem. Essa cobrança, quando 18 feita de forma equilibrada, é indispensável aos governos republicanos democráticos, visto que 19 orienta os governantes a tomarem decisões em acordo com os interesses das sociedades que 20 representam.

21 Diante do exposto, observa-se que o voto nulo consiste em um ato político ineficaz, uma vez 22 que, além de causar pouco impacto sobre os agentes do Estado, facilita a ascensão de 23 candidatos desonestos. É necessário, portanto, que a sociedade repense essa forma de protesto, 24 de modo que as eleições recuperem seu caráter transformador da realidade.

Acima é apresentada uma redação na íntegra e que foi selecionada por ser exemplo prototípico de um texto organizado, que apresenta progressão temática e uma linha clara de raciocínio, mas que não consegue atingir uma nota mais alta no critério B exatamente porque, em alguns momentos, possui lacunas que impedem uma maior densidade argumentativa. A tese, apresentada ao final do primeiro parágrafo, é a de que o voto nulo não é um ato político eficaz. Nos dois parágrafos seguintes, os argumentos que sustentam essa tese são apresentados: votos nulos não invalidam o processo eleitoral (linhas 07 e 08); os eleitores que anulam os votos são, em geral, aqueles com maior senso crítico, o que favorece que candidatos menos honestos sejam eleitos (linhas 09 a 12); votos nulos não causam incômodo efetivo sobre os governantes, mas, ao contrário, podem ser interpretados como apatia da sociedade, o que reduz a pressão social que tais representantes sofrem (linhas 14 a 18). O texto é finalizado com uma proposta de ação efetiva ainda no terceiro parágrafo (a cobrança deve ser feita de forma equilibrada, nas linhas 19 a 21) e, no parágrafo final, é feita uma breve retomada dos argumentos apresentados que apontariam para a necessidade de a sociedade repensar a pertinência do voto nulo como forma de 
protesto a fim de possibilitar que as eleições recuperam seu caráter transformador da realidade. Como se vê, as relações de causa e consequência são absolutamente claras e plausíveis. Além disso, observa-se que o texto foi devidamente planejado e que a escolha da sequência dos parágrafos não é aleatória: pelo contrário, há uma progressão bastante adequadas dos temas abordados. Porém, é possível identificar uma superficialidade nos argumentos, exatamente pela falta de desenvolvimento dos dados, fatos e ideias apresentados nos segundo e terceiro parágrafos. Essa falta não se observa na introdução, em que há pleno desenvolvimento das questões abordadas: afirma-se que o voto nulo é um tema de grande relevância na atualidade e, em seguida, essa afirmação é sustentada por exemplos concretos da última eleição (o alto percentual de abstenções em duas capitais do Brasil). Já os dois parágrafos apresentam algumas lacunas: na linha 07, afirma-se que há uma crença popular de que a expressividade dos votos invalida o processo eleitoral. Existe essa crença? É possível que o leitor tenha conhecimento desse mito amplamente difundido, especialmente nas redes sociais. Mas, considerando a função argumentativa da dissertação, esse argumento ganharia muito mais densidade se acompanhado de uma referência à divulgação desse mito. Por exemplo, uma reescrita possível seria: as redes sociais difundiram, amplamente, o mito de que uma quantidade expressiva de votos nulo seria suficiente para anular as eleições. No entanto, isso não é verdade: nosso sistema eleitoral não prevê anulação por esse motivo, o que significa que algum candidato será, necessariamente, eleito - aquele com o maior percentual de votos válidos. O segundo argumento é também pouco embasado: o de que o cidadão que anula o voto como forma de protesto é um eleitor com razoável senso crítico (linhas 09 e 10). Qual é a base dessa afirmação? Ela não é óbvia, nem livre de polêmicas. $\mathrm{O}$ ato de protestar (seja por passeatas ou, supostamente, por meio do voto nulo) não indica, necessariamente, consciência e senso crítico apurado. Depois, nas linhas 14 a 16, afirma-se que o voto nulo não produz incômodo efetivo nos governantes e pode ser interpretado como apatia da sociedade: por quê isso ocorre? Qual a relação entre voto nulo e apatia, considerando que para muitos é exatamente uma forma ativa de protesto? Em seguida, é apresentada a proposta de que uma cobrança feita de maneira equilibrada poderia orientar os governantes a tomarem decisões em acordo com os interesses da sociedade (linhas 19 a 21). O que é, concretamente, uma cobrança feita de forma equilibrada? Como ela se opõe ao voto nulo que, implicitamente, é definido como uma cobrança sem equilíbrio? Como essa cobrança equilibrada levaria os governantes a terem uma postura mais responsável? Por fim, quando a conclusão indica que uma reflexão crítica sobre o voto nulo pode tornar possível que as eleições recuperem sen caráter transformador, pode-se questionar: as eleições têm esse caráter? Transformador em que sentido? 
Como as eleições fomentam essa transformação? Percebe-se, assim, que embora os argumentos tenham uma relação direta com a tese, a falta de desenvolvimento dos mesmos, que abre espaço para muitos questionamentos, indiciam um potencial fragilizado de convencimento e é nesse sentido que os argumentos serão avaliados como superficiais em alguns momentos.

A análise do exemplo 1 aponta para a produtividade da ideia de lacuna na análise de redações que embora adequadas, apresentam argumentos não plenamente desenvolvidos. A ideia de superficialidade, nesse contexto, não tem a ver com falta de originalidade nem está associada a um conhecimento profundo de certas áreas de conhecimento. Não se espera que o candidato demonstre um conhecimento especializado em ciências políticas, por exemplo, para conseguir produzir uma dissertação de vestibular consistente e com argumentos não superficiais sobre o voto nulo. O papel dos textos motivadores é, inclusive, prover informações básicas sobre o tema para que o candidato tenha subsídios mínimos para a construção de seu texto.

Certamente, as lacunas não chegam a impedir a compreensão do texto acima, o que indica que em textos mais bem organizados e que apresentam o bom uso dos recursos linguísticos, identificar lacunas possibilita encontrar na materialidade linguística onde está o problema. De fato, a mobilização de um conhecimento de mundo - parte essencial de qualquer processo de leitura - ou a convocação de uma memória (em especial, no termos proposto por Achard (1983), para quem os implícitos a que um dado enunciado faz apelo remetem exatamente a uma memória discursiva), poderia, eventualmente, preencher as lacunas: no exemplo 1, é o caso da referência à crença popular de que um alto percentual de votos nulos invalida a eleição; ou de que quem anula é alguém que tem senso crítico; ou de que as eleições têm o poder de transformar a realidade. No entanto, os limites de explicitude ou implicitude de um texto são definidos, em boa medida, pelo gênero (sua função social, formas e meios de circulação, leitores previstos, etc.). Em uma poesia concreta, por exemplo, a frouxidão das relações de sentido não é, de fato, um problema: pelo contrário, é constitutivo do gênero. No caso das dissertações escolares, considerando exatamente sua função persuasiva, explicitar a relevância dos argumentos para a defesa do ponto de vista é estratégia central em uma argumentação deliberativa (voltaremos a esse ponto mais à frente).

O próximo exemplo apresenta uma redação que foi avaliada com a nota máxima no critério B. O exemplo anterior evidenciou o que é uma lacuna. $\mathrm{O}$ próximo permitirá visualizar com mais clareza o que significa, neste contexto, um argumento desenvolvido. 


\section{Exemplo 2}

01 O processo eleitoral ocorrido no Brasil em 2016 foi marcado pelo cenário de turbulência vivido 02 pelo país, em que foram descobertos diversos casos de corrupção, envolvendo políticos de 03 renome, potencializado pela grave crise econômica brasileira. Nesse contexto, muitas correntes 04 de discussão passaram a defender a adoção do voto nulo nas eleições como forma de 05 demonstrar a insatisfação da população em relação ao sistema político vigente. Contudo, uma 06 análise mais profunda sobre o tema sugere que esse ato não representa, de fato, uma maneira 07 efíciente de contestação e de estímulo à mudança política.

$08 \mathrm{Em}$ primeiro lugar, é preciso explicitar que, ao votar nulo, o indivíduo nega o principal 09 benefício concedido aos cidadãos dentro da democracia, representado pela autonomia de 10 escolher seus governantes e os rumos das políticas públicas. Esse direito está intrinsicamente 11 ligado ao modelo democrático desde os seus primórdios, já que, na Antiguidade, os gregos se 12 reuniam em Assembleias para decidir o futuro da polis. Desse modo, não se posicionar, por 13 meio do voto, no processo eleitoral, vai de encontro aos princípios inerentes à plena 14 democracia, tão almejada no Brasil atualmente. Além disso, esse ato se constitui como um 15 meio de desvalorização das conquistas obtidas ao longo da história brasileira. Nesse sentido, 16 deve-se destacar a atuação do movimento Diretas Já, que através de intensa articulação social, 17 foi um dos responsáveis pela consolidação do sistema eleitoral nos moldes atuais.

18 Em segundo lugar, é necessário compreender que o sufrágio é apenas o último estágio de um 19 processo social e político muito mais amplo, que envolve a formação do cidadão, o 20 comprometimento das pessoas com a comunidade e, em última instância, culmina na escolha 21 de candidatos preparados para a administração pública. Em países exemplos de gestão política, 22 como a Noruega e o Canadá, nota-se o alto grau de esclarecimento político da população e sua 23 participação ativa na manutenção do bem-estar coletivo, características pouco observadas no 24 Brasil. Assim, conclui-se que a adoção do voto nulo, de maneira desarticulada a outras medidas 25 de conscientização da sociedade, não representa um canal eficiente de se contestar as estruturas 26 políticas vigentes e de aperfeiçoá-las.

27 Em suma, comprova-se a importância do direito ao voto na construção da democracia e de que 28 como, ao optar por não escolher um governante, o cidadão desvaloriza a atuação dos 29 movimentos que lutaram por esse direito. Ademais, é essencial a percepção de que a ação de 30 votar nulo, dissociada da busca pela maior participação da sociedade no processo social e 31 político, não apresenta resultados contundentes na melhora do modelo político vigente.

Neste exemplo também é apresentada uma redação na íntegra, com o objetivo de demonstrar o que é entendido como uma argumentação sem lacunas. A redação é composta de quatro parágrafos: a introdução, em que é o tema do voto nulo é contextualizado e a pertinência da sua discussão, justificada a partir da referência à turbulência do processo eleitoral de 2016 (explicitam-se dados e fatos que sustentam essa afirmação: a descoberta de casos de corrupção envolvendo políticos de renome e o agravamento da crise econômica); nesse parágrafo introdutório é também apresentada a tese, a saber, de que o voto nulo não é uma maneira eficiente de contestação e de estímulo a mudança política. Os dois próximos parágrafos são dedicados ao desenvolvimento, em que três argumentos que sustentam a tese são apresentados: ao votar nulo, o indivíduo nega o principal benefício concedido aos 
cidadãos dentro da democracia (linhas 08 e 09); votar nulo se constitui como um meio de desvalorização das conquistas obtidas ao longo da história brasileira (linhas 14 e 15); o sufrágio é apenas o último estágio de um processo social e político mais amplo (linhas 18 e 19). No parágrafo conclusivo, é feita uma síntese do que foi anteriormente defendido, com a retomada da tese, de modo a explicitar como o percurso argumentativo construído conduz à tese defendida. Assim como no exemplo anterior, observa-se progressão temática, organização dos parágrafos e argumentos que dialogam diretamente com a tese defendida. A diferença, no entanto, está no desenvolvimento dos argumentos. Abaixo, para cada argumento, explicito os desenvolvimentos apresentados:

- ao votar nulo, o indivíduo nega o principal benefício concedido aos cidadãos dentro da democracia: primeiramente, há uma explicitação de que o principal benefício é representado pela autonomia de escolha dos representantes, seguida da retomada da ideia de que esse direito é parte da essência da democracia a partir da referência ao papel do voto na Grécia Antiga. Não votar seria, assim, ir de encontro aos princípios inerentes à própria democracia;

- votar nulo se constitui como um meio de desvalorização das conquistas obtidas ao longo da bistória brasileira: o que se segue à apresentação desse argumento é a explicitação de um evento histórico em especial - o movimento Diretas Já - e que conquistas foram essas - a consolidação do sistema eleitoral nos moldes atuais (que, conforme afirmado anteriormente, constitui-se, essencialmente, pelo direito ao voto);

- o sufrágio é apenas o último estágio de um processo social e político mais amplo: esse argumento desdobra-se em um trabalho de explicitação do que está sendo entendido por processo social e político mais amplo. Ele envolve formação do cidadão e comprometimento das pessoas com a comunidade, o que confere condições para uma escolha adequada de candidatos. Dois exemplos de países reconhecidamente bem-sucedidos na gestão pública (aqui, apela-se a uma memória) - Noruega e Canadá - são citados como estratégia de comprovação do que o que está sendo dito tem respaldo na realidade.

Assim, observa-se, nessa redação, um cuidado em guiar a leitura, deixando pouco espaço para dúvidas sobre qual o ponto de vista defendido ou sobre o por quê de um determinado fato ser referenciado. É nesse sentido que essa redação é avaliada como apresentando argumentos bem desenvolvidos e que convergem para o ponto de vista definido.

A análise do exemplo 2 destaca algumas características daquilo que está sendo definido como argumentos desenvolvidos, isto é, não superficiais. Trata-se, 
acima de tudo, de um cuidado, por parte do candidato, em ancorar o sentido do seu texto em elementos que orientam a leitura, que guiam a interpretação do leitor. Disso resulta uma certa imagem de enunciador ou, nos termos de Maingueneau $(2005,2010)$, faz emergir um ethos específico.

Até aqui, fiz um percurso que mostra a importância da definição de critérios de avaliação que sejam tanto aplicáveis no contexto específico de avaliação de redações de vestibular, quanto teoricamente embasados, de modo a identificar traços nos textos dos candidatos que indiquem, da forma mais consistente possível, o nível de proficiência em escrita (mais especificamente, no caso ora em análise, da escrita de textos argumentativos). Em seguida, apresentei análises de redações que foram avaliadas com notas acima da média, a fim de demonstrar que o conceito de lacuna é especialmente funcional na tarefa de diferenciar textos adequados daqueles que cumprem plenamente a tarefa definida pela prova. Agora, uma nova pergunta se coloca: por que o desenvolvimento dos argumentos, o que evita as lacunas, favorece, de maneira especial, o texto, a ponto de diferenciá-lo de outro texto que é, também, bom e organizado?

\section{O ETHOS DO ENUNCIADOR EM DISSERTAÇÕES DE VESTIBULAR}

Minha hipótese é que esses desenvolvimentos contribuem de forma importante para a constituição do ethos discursivo do enunciador. A noção de ethos aqui retomada é aquela proposta por Maingueneau $(2005,2010)$, que a partir da tradição retórica, reformula a noção no quadro teórico da análise do discurso de tradição francesa. Sua proposta afasta-se, portanto, de uma relação necessária com qualquer eloquência ou mesmo com discursos orais e, neste sentido, o autor afirma: "qualquer discurso escrito, mesmo que a negue, possui uma vocalidade específica, que permite relacioná-lo a uma fonte enunciativa, por meio de um tom que indica quem o disse" (Maingueneau, 2005: 72).

A ideia de que todo texto libera um ethos significa que a leitura faz emergir uma origem enunciativa, uma instância subjetiva encarnada que exerce o papel de fiador, detentor tanto de um caráter (um traço de feixes psicológicos) quanto de uma corporalidade (uma compleição corporal, uma forma de mover-se, de estar no mundo). Trata-se, de fato, do corpo do enunciador (e não do autor efetivo), e que se permite ver a partir de indícios de diversas ordens que são materializados no texto: escolhas lexicais, maior ou menor concordância com a norma culta da língua, complexidade da sintaxe, uso de parênteses, ironias, referência a certos fatos relacionados à cultura erudita ou popular, etc. Sua diamagração, tamanho e tipo da 
fonte, o médium, cores e, eventualmente, imagens associadas, também carregam o enunciado de um ethos específico.

Alguns tipos e gêneros de discurso favorecem que o público construa uma representação do ethos do enunciador antes mesmo de ler/ouvir o texto. Fala-se, assim, em um ethos pré-discursivo, caso, por exemplo, de textos que compõem campanhas eleitorais de um determinado candidato ou textos produzidos por figuras públicas em geral. É possível, também, diferenciar um ethos dito de um mostrado. A análise que Maingueneau (2010) faz de anúncios redigidos por postulantes em sites de relacionamentos da internet mostra claramente a diferença entre o ethos dito, dado a conhecer por meio de informações que o locutor dá sobre si mesmo (tanto de ordem social, como local de residência, estado civil, idade, remuneração, por exemplo, quanto de ordem psicológica, como personalidade, gostos, etc.) e um ethos mostrado, que emerge nos pequenos textos produzidos pelos candidatos com o objetivo de se apresentarem aos possíveis interessados em iniciar um relacionamento. Aqueles elementos, apresentados em uma ficha cujas categorias são pré-definidas pelo site de relacionamentos, produzem um ethos não discursivo, ainda que ativem estereótipos em mundos éticos que associam, de forma mais ou menos direta, comportamentos a traços de caráter. Para Maingueneau, o ethos propriamente discursivo será aquele que é da ordem do mostrado, construído pelo leitor a partir de indícios dados na enunciação: "a questão essencial é que o ethos [...] está ligado à enunciação, e não a um saber extradiscursivo sobre o enunciador" (2005, p.70).

É importante ressaltar que a noção de ethos discursivo não supõe que o enunciador seja um ponto de origem estável, que de forma absolutamente consciente faz escolhas que permitem a emergência de um ethos controlado. O enunciador é, de fato, um dos elementos de um quadro profundamente interativo, que numa dada configuração histórica e social, implica papeis, lugares e momentos de enunciação legítimos, um suporte material e um modo de circulação para o enunciado:

Na perspectiva da análise do discurso, não podemos, pois, contentar-nos, como na retórica tradicional, em fazer do ethos um meio de persuasão: ele é parte constitutiva da cena de enunciação, com o mesmo estatuto que o vocabulário ou os modos de difusão que o enunciado implica por seu modo de existência (MAINGUENEAU, 2005, p.75)

Mobilizando o conceito de ethos discursivo para analisar como as lacunas prejudicam as dissertações produzidas em um vestibular, proponho caracterizar os desenvolvimentos que preenchem "lacunas em potencial", analisadas nos exemplos anteriores, como elementos que contribuem para uma construção bem-sucedida do ethos do enunciador dessas dissertações. E, analogamente, caracterizar sua 
presença como elementos que interferem negativamente para a emergência de um ethos ideal.

As dissertações argumentativas, como já mencionado, se caracterizam por serem um texto tipicamente escolar em que um determinado assunto deve ser discutido, a partir da defesa de um ponto de vista claro a respeito desse assunto, que deve ser apresentado com o objetivo de convencer o leitor. Neste sentido, a descrição que Vigner (1974: 110) nos oferece é bastante elucidativa. Para o autor, ensinar a dissertar é ensinar o aluno a dizer o que ele pensa sobre um determinado tema, isto é, "a confrontar experiências, compará-las, apreciá-las, julgá-las, transmitir pontos de vista, fazer com que o interlocutor mude de opinião". Tal exercício de expressão da opinião demanda o domínio de estratégias não apenas linguísticas, mas também discursivas, que são específicas da argumentação. Para esse autor,

\begin{abstract}
a argumentação encontra-se na confluência da retórica (da qual empresta a noção de auditório, que organiza a mensagem) e da lógica (que lhe fornece procedimentos de demonstração indispensáveis à sustentação de certas afirmações), como assinala M. J. Borel: "uma das características da argumentação é a de justificar uma ou várias afirmações. Neste sentido, pode-se pressupor a existência de mecanismos que encadeiam as proposições com a finalidade de sustentar racionalmente algumas delas". (VIGNER, 1974, p.112)
\end{abstract}

Essa descrição está fortemente fundada na retórica, e tem em seu horizonte uma argumentação tipicamente deliberativa, em que se visa chegar a um consenso sobre a melhor solução para o problema posto. De fato, as dissertações escolares são um exercício deliberativo: não visam um embate violento, marcado pelas paixões. $\mathrm{O}$ exercício das dissertações escolares é, como bem aponta Vigner (retomando Borel), um exercício que se situa entre a lógica e a retórica.

Amossy (2017), em um vasto estudo sobre a polêmica, propõe uma concepção modular da argumentação como um continuиm em que em um dos polos estariam situados discursos persuasivos que não atacam explicitamente a posição contrária; no centro, a troca regrada de teses antagônicas; e, no outro polo, o choque insolúvel entre dois posicionamentos, em que o consenso se mostra impossível. Uma das teses centrais da autora é a negação de que o confronto polêmico esteja fora da argumentação, como afirma a doxa: de fato, Amossy irá defender as racionalidades alternativas que regem o funcionamento polêmico - entendido como uma argumentação cuja função não é o acordo entre as partes - e a essencialidade desta modalidade argumentativa para a configuração e funcionamento das sociedades democráticas. Neste sentido, mais do que uma mudança de status (a deliberação como exercício do logos e a polêmica como manifestação do pathos), o que se observa na proposta da autora é uma mudança da configuração argumentativa a depender 
do ponto no continuum em que um determinado debate se situa. A dissertação argumentativa, enquanto exercício escolar, está assim fortemente associada à retórica de tradição aristotélica, que busca o acordo pela mobilização da razão e do bom-senso. Como explica Amossy (2017, p. 19),

Nessa perspectiva [da retórica aristotélica], a deliberação deve obedecer aos ditames da razão: ela é, por definição, o trabalho do logos, ou seja, a fala como discurso e razão. Aqueles que deliberam sobre uma questão controversa apresentam argumentos que permitem pesar os prós e os contras de cada tese, a fim de alcançar uma resposta comumente aceita. [...] Toda deliberação deve essencialmente seguir vias racionais se quiser resolver conflitos de opinião através do uso da fala.

Trata-se, em suma, da encenação de uma fala arrazoada, controlada, que se afasta radicalmente do debate inflamado, da fala marcada pela violência verbal e cujo objetivo é destruir o adversário por quais meios forem necessários.

As provas de redação em vestibulares, enquanto exames seletivos, impõem ao candidato demonstrar uma habilidade escritora que é condizente com a de um indivíduo apto a ocupar uma vaga no Ensino Superior. Mas, quanto mais avançada seja essa habilidade, mais apagada do texto será a imagem desse sujeito empírico, isto é, do candidato. O texto não deve permitir a emergência da imagem de um jovem aluno concluinte do Ensino Médio, mas sim do enunciador prototípico das dissertações escolares, de um fiador condizente com essa enunciação que, como vimos, é marcada pela razão. Deve, assim, ser um enunciador condizente com esse debate arrazoado, um indivíduo por meio de quem a voz da razão emana: a fonte de legitimação desse dizer não é o indivíduo, mas a razão.

Assim, toda a materialidade linguística do texto, em sua completude, será mais adequada quanto mais convergir para emergência de um caráter racional, atendendo a uma expectativa prevista para o contrato (tácito) de comunicação que subjaz a produção de dissertações: o candidato mostra sua competência escritora ao se colocar em segundo plano na sua enunciação. Trata-se, de fato, como propõe Maingueneau, de locutores que encenam uma fala.

Esse tipo de fenômeno pede uma discussão ampla e cuidadosa do gênero redação de vestibular, além de colocar em evidência a complexa relação entre sujeito empírico e sujeito do discurso. Essas questões, profundamente complexas, se desviam dos propósitos definidos para o presente trabalho. Mas é essencial, no contexto da presente discussão, apontar essa situação paradoxal, intimamente relacionada ao gênero discursivo, que impõe ao candidato dominar regras de produção - que refletem exigências tanto intra (o gênero, o tema, a quantidade linhas mínima e máxima, o registro, a língua, os mecanismos linguísticos e textuais 
de construção da argumentação, etc.) quanto extratextuais (o local da prova, a cor da caneta com que se deve escrever o texto, o documento que deve ser apresentado aos fiscais, onde escrever o texto definitivo, etc.) - e, a partir delas, construir uma imagem de si adequada, por meio de sua enunciação, que apaga o sujeito empírico e dá corpo a uma entidade exclusivamente discursiva.

Em alguma medida, podemos considerar que, assim como no corpus de análise selecionado por Maingueneau em seu artigo de 2010 (anúncios redigidos por postulantes em sites de relacionamentos da internet), os actantes das redações (os candidatos) devem fazer os destinatários (a banca avaliadora) aderirem a uma apresentação de si valorizada. No entanto, há diferenças cruciais entre os dois modos de enunciação: nos sites de relacionamentos, junto do ethos discursivo, há um ethos dito; além disso, as variações do ethos admitidas pelo gênero são muitas, já que variam tanto quanto variam as personalidades das pessoas: os anunciantes podem se mostrar como uma pessoa extrovertida, aventureira, requintada, acolhedora, amigável, etc. Já nas redações, essa imagem de si não deriva de algo que o candidato fala explicitamente sobre seu conhecimento de língua e de escrita, mas de como ele a constrói a partir de sua enunciação. Trata-se de uma imagem que deriva exclusivamente do texto: o anonimato absoluto, o desconhecimento, por parte da banca avaliadora, do percurso acadêmico prévio e, inclusive, da performance nas demais provas do processo seletivo, faz da prova de redação um caso de construção de um ethos discursivo puro, sem que haja interferência de um ethos pré-discursivo. A redação é a carta de apresentação do candidato. E considerando que o gênero solicitado é uma dissertação, não há qualquer espaço para um ethos dito. Pelo contrário: como já apontado, o sujeito real deve ser completamente apagado. Paradoxalmente, por esse apagamento, ele indicia que possui o domínio da escrita que se espera para o início de uma nova etapa de escolarização. $\mathrm{O}$ ethos das dissertações de vestibular constitui-se, assim, nesse jogo de apagamento e visualização do sujeito real.

O caráter desse enunciador deve ser, invariavelmente, o de um indivíduo dotado de razão - o orador deliberativo da retórica -, que consegue ver a problemática de que trata de forma ampla e que, por isso, sabe qual o posicionamento mais adequado e racional a ser assumido. É um enunciador convincente, seguro de seu posicionamento e que domina sua enunciação.

Retomando os exemplos 1 e 2 já analisados, percebemos que esse ethos razoável é projetado, em ambas as redações, pela organização dos parágrafos (há progressão temática adequada decorrente de um visível planejamento prévio à escrita) e pela ausência de problemas de ordem textual mais evidentes (não há problemas de 
construção frasal, de ortografia, de escolha lexical inadequada, etc.). Além disso, em ambos os textos, os argumentos selecionados estão claramente associados ao tema em discussão (a validade do voto nulo para modificar o cenário político nacional). Porém, no primeiro exemplo, como indicado na análise, observa-se a presença de afirmações categóricas que, embora não prejudiquem, efetivamente, a compreensão do texto, produzem um efeito de falta de controle: é como se ao não explicitar, por exemplo, o que se quer dizer com "cobrança feita de maneira equilibrada" ou o que permite afirmar que "o cidadão que anula o voto com base em uma motivação política é, em geral, um eleitor com razoável senso crítico", o enunciador projetasse uma imagem de alguém que não domina, efetivamente, a totalidade da cena enunciativa: sabe do que fala, mas não para quem fala. Ao desenvolver esses pontos da sua argumentação, o efeito é de antecipação dos questionamentos possíveis aos argumentos apresentados - o que remete para o co-enunciador de seu texto. É o que acontece na segunda redação analisada: todo o desenvolvimento feito, por exemplo, para a afirmação de que "o sufrágio é parte de um processo social e político mais amplo", indicia uma antecipação de reações possíveis a essa afirmação. É possível perguntar: que processo social e político mais amplo é esse? E como o ato de votar se relaciona a esse cenário mais amplo? Ambas as perguntas são respondidas (essas respostas são, de fato, o que está sendo considerado como desenvolvimento), de modo a produzir um efeito de convencimento na medida em que antecipa reações que poderiam invalidar ou fragilizar o argumento apresentado. Assim, observa-se que, ao preencher as "lacunas" em potencial, o enunciador demonstra um domínio da totalidade da cena: sabe do que fala e para quem fala.

De fato, associada à noção de ethos, Maingueneau propõe, também, a noção de incorporação, que designa a relação que se dá entre co-enunciador e o ethos de um discurso. Isto é, o ethos deriva da delimitação de um lugar não só para o próprio enunciador do texto, mas também para o co-enunciador, cuja posição pode ser de adesão ou não frente ao enunciado. $\mathrm{O}$ modo de se expressar designa, portanto, um lugar para o seu co-enunciador, cuja mobilização frente a um discurso está em boa medida atrelada aos processos de incorporação que esse discurso desperta, que, por sua vez, decorrem dessa voz e desse corpo que se constrói na enunciação.

Neste sentido, a imagem de co-enunciador que emerge das dissertações deve se afastar, em alguma medida, dos sujeitos reais que irão ler as redações, no seguinte sentido: não se deve supor, por exemplo, que certas informações sobre o tema são óbvias - afinal, a banca conhece a prova e qual o tema que está em discussão. De fato, supõe-se que o texto se dirige a um leitor autônomo: ela poderia ser lida por qualquer pessoa e "fazer sentido", são textos que poderiam circular no mundo. 
Trata-se, de fato, de outro paradoxo que o gênero apresenta: os textos terão uma circulação absolutamente restrita - só serão lidos pela banca examinadora, (ainda que eventualmente sejam publicados em algum site, revista ou livro especializado, essa não é a sua função: redações de vestibulares não "nascem" com esse propósito) - mas o candidato deve ficcionalizar que o seu texto irá circular no mundo e, a partir disso, construir a imagem do seu co-enunciador: um indivíduo qualquer dotado de razão e que pode ser convencido por meio de uma argumentação potente - o que demanda a devida contextualização do problema a ser debatido. Observa-se, assim, um movimento que descola os seres do mundo extratextual - candidatos e bancas avaliadoras - das instâncias que a enunciação constrói.

O ethos racional das dissertações deriva da totalidade do texto, certamente, e não apenas das estratégias específicas mobilizadas para a argumentação. Mas minha hipótese é que existem níveis mais explícitos e outros mais sutis de elementos que garantem a emergência desse ethos nas dissertações de vestibular. A adequação aos traços mais prototípicos da dissertação equivaleria a um nível mais óbvio deste ethos previsto para o gênero: é preciso que o texto se apresente em conformidade com uma estrutura composicional prototípica (introdução, desenvolvimento e conclusão), que não seja narrativo, que atenda à norma culta da língua, que se expresse em um registro formal. Essas seriam as condições mínimas. Mas, certamente, não suficientes: além disso, as escolhas lexicais adequadas e precisas e o emprego de estruturas sintáticas e de mecanismos coesivos mais complexos irão, também, convergir com o ethos racional que se espera. A ausência de lacunas equivaleria, se pensarmos nesse ethos que se constrói em camadas, aos níveis mais sutis. Ela indica, de uma forma menos evidente, um domínio que o candidato tem da enunciação, que se mostra a partir desse trabalho de explicitação e que funciona, em boa medida, como esteios do sentido: os desenvolvimentos argumentativos controlam a dispersão dos sentidos, nos termos de Tfouni $(2001,2008)$.

A autora propõe, assumindo como bases teóricas a análise de discurso pêcheutiana e a psicanálise lacaniana, que a autoria resulta de um trabalho de ancoragem, numa tentativa de controle da inevitável deriva dos sentidos. Para ela, "o sujeito ocupa a posição de autor quando retroage sobre o processo de produção de sentidos, procurando 'amarrar' a dispersão que está sempre virtualmente se instalando, devido à equivocidade da língua" (TFOUNI, 2008, p.71). A dispersão é, desta perspectiva, controlável a partir de recursos que são da ordem do sistema da língua.-

A ideia de um trabalho que visa amarrar os sentidos e evitar a dispersão é muito precisa e produtiva para as análises das lacunas e desenvolvimentos nas 
dissertações de vestibular, ainda que o arcabouço mobilizado, assim como o tipo de corpora e, mais ainda, os fenômenos analisados, se afastem da proposta de Tfouni. Além disso, não se trata, aqui, de discutir nem o conceito, nem a constituição da autoria em textos em geral ou em dissertações de vestibular. Porém, assumir que os desenvolvimentos que evitam as lacunas nas dissertações dos vestibulandos são "um movimento de contenção que produz um efeito de controle da dispersão" (TFOUNI, 2001, p. 86) possibilita afirmar que este fenômeno, observável em redações acima da média, é um tipo de fenômeno textual-discursivo mais sutil e que materializa a encenação de um dizer razoável. Disso decorre a imagem de um enunciador que encena a produção de um sentido claro e controlado. Trata-se, enfim, de um enunciador que, tomado de bom senso, sabe onde quer chegar com o seu dizer e que domina os pontos de seu texto que podem levar a sentidos não desejados ou mesmo incompreendidos.

\section{CONCLUSÃO}

Este trabalho teve como objetivo apresentar uma reflexão, a partir de uma experiência vivida há alguns anos, sobre os desafios inerentes à prática de avaliação de textos produzidos em condição de vestibular. E, considerando esse contexto específico de avaliação, busquei mostrar como o conceito de lacuna atende às demandas de aplicabilidade e robustez teórica. A questão da aplicabilidade não foi abordada por um viés psicométrico, mas considerando o tipo de análise necessária para identificar lacunas ou reconhecer sua ausência. Ou seja, não se tratou, considerando o escopo definido para este trabalho, essencialmente ancorado em questões de texto e discurso, de abordar a aplicabilidade pelo viés psicométrico. Para tanto, seria necessário apresentar dados estatísticos com índices de discrepância e produtividade, por exemplo, como comprovação de que o conceito garante "níveis adequados de concordância". No entanto, isso não foi feito, por algumas razões, dentre as quais destaco uma: analisar que o conceito de lacuna é operacional a partir dessa perspectiva traria para o centro das discussões aqui propostas aspectos da avaliação que já são amplamente discutidos na literatura em avaliação educacional. Haveria, nesse sentido, um desvio dos propósitos estabelecidos para este trabalho: o de refletir sobre a avaliação de testes de escrita não pelo viés psicométrico, mas com foco nas questões específicas de texto e discurso. De fato, acredito que a grande questão que se coloca no horizonte daqueles que se veem com a reponsabilidade de definir critérios de avaliação em testes dessa natureza é (ou deveria ser), acima de tudo, a fundamentação teórica que orienta as decisões de análise que levam 
a pontuação dos textos. Se se quer critérios que não sejam arbitrários e que contribuam, de alguma forma, para as práticas de ensino de escrita, antes de buscar concordância entre avaliadores, é preciso definir com clareza e propriedade teórica o que será avaliado especificamente em termos de textualidade.

Assim, a análise aqui apresentada sobre o conceito de lacuna buscou trazer para o centro do debate exatamente as questões que são específicas da análise textual que se mostra necessária no contexto de avaliação em larga escala. Neste sentido, a metáfora de que o conceito é a ponta do iceberg expressa exatamente sua operacionalidade, cuja sustentação é garantida por uma teoria sólida (e "submersa" aos olhos dos avaliadores) a respeito de como o sentido é produzido. Considerando, especificamente, a função avaliativa e classificatória das redações, tentei mostrar como o conceito de lacuna é feliz ao indicar, na superfície do texto, decisões complexas, cujo alcance nem sempre é consciente, que indiciam um domínio da escrita por parte do candidato.

É possível questionar - na verdade, é preciso questionar - se o domínio da escrita de dissertações argumentativas é suficiente para afirmar que alguém sabe escrever (no sentido pleno), na medida em que sabemos o quanto há de treino para essa escrita e o quanto é deixado de lado nas salas de aula pela relevância dos testes dessa natureza no percurso acadêmico dos alunos. É preciso refletir, enfim, sobre a natureza dessas provas e sobre seus efeitos sociais, de maneira mais ampla, como bem indica Moss (1994). Porém, considerando os limites dessa avaliação, que inescapavelmente avalia o conhecimento da escrita de dissertações, busquei mostrar que o conceito de lacuna é bem-sucedido na complexa tarefa de fazer coexistir teoria robusta e aplicabilidade.

\section{$\overline{\text { REFERÊNCIAS }}$}

ACHARD, P. (1983) Memória e produção discursiva do sentido. In: ACHARD, P. et al. (org). Papel da Memória. Tradução e Introdução de José Horta Nunes. Campinas: Pontes, 1999, pp. 11-22.

AMOSSY, R. (2014) Apologia da polêmica. Tradução coordenada por Mônica Magalhães Cavalcanti. São Paulo: Contexto, 2017.

BRITO, L. A. N. (2011). Discurso, leitura e produção textual: uma análise discursiva da escrita de préuniversitários. Tese de Doutorado em Linguística. Faculdade de Filosofia, Letras e Ciências Humanas, Universidade de São Paulo. 
DE LEMOS, C. T. G. (1977). Redações no vestibular: algumas estratégias. Cadernos de Pesquisa, n. 23, pp. 61-71.

DUCROT, O. Argumentação e 'topoi' argumentativos. Tradução de Eduardo Guimarães. In: GUIMARÃES, E. (Org.). História e Sentido na linguagem. Campinas: Pontes, 1989, pp. 13-38.

ESVAEL, E. V. S. (2011). Estratégias argumentativas na construção de pontos de vista em redações de vestibular. In: Anais do VII Congresso Internacional da Abralin. Curitiba, pp. 1241-1254.

FIAD, R. S. (2000). A argumentação em cartas produzidas por alunos do Ensino Médio: relação entre gênero do discurso e estilo. Trabalhos em Linguística Aplicada, v. 36, pp. $131-145$.

FIORIN, J. L. Argumentação. São Paulo: Contexto, 2015.

FOSSEY, M. F. (org). O processo de avaliação de redações na Fundação VUNESP. São Paulo: Cultura Acadêmica Editora, 2017.

HUOT, B. (1996). Toward a new theory of writing assessment. College Composition and Comunication, v. 47 , n. 4 , pp. 549-566.

KELLY-RILEY, D; WHITHAUS, C. (editores). The Journal of Writing Assessment: "Special Issue on a Theory of Ethics for Writing Assessment", v.9 (1), 2016.

MACIEL, L. V. C. (2010). Vestibular da Unicamp: uma proposta dialógica de redação. Revista Brasileira de Linguística Aplicada, v. 10, pp.159-177.

MAINGUENEAU, D. Ethos, cenografia, incorporação. Tradução de Sírio Possenti. In: AMOSSY, R. (org.) Imagens de si no discurso: a construção do ethos. São Paulo: Editora Contexto, 2005, pp. 69-92.

MAINGUENEAU, D. Ethos e a apresentação de si nos sites de relacionamento. Tradução de Luciana Salgado. In: SOUZA-E-SILVA, M. C. P.; POSSENTI, S. (orgs). Doze conceitos em Análise do Discurso. São Paulo: Parábola Editorial, 2010, pp. 79-98.

MOSS, P. (1994). Can there be validity without reliability? Educational Researcher, n. 23, v. 2, pp. 5-12.

OSAKABE, H. (1977). Redações no vestibular: provas de argumentação. Cadernos de Pesquisa, n. 23, pp. 51-59. 
PÉCORA, A. Problemas de redação. São Paulo: Martins Fontes, 1986.

PIETRI, E. (2007). A constituição da escrita escolar em objeto de análise dos estudos linguísticos. Trabalbos em Linguística Aplicada, v. 46, pp. 283-297.

PILAR, J. A redação como gênero. In: MEURER, J. L.; MOTTAROTH, D. (orgs.). Gêneros textuais e práticas discursivas. Rio de Janeiro: Lucerna, 2001, pp. 159-174.

SCARAMUCCI, M. V. R. Prova de redação nos vestibulares: educacionalmente benéfica para o ensino/aprendizagem da escrita? In: Flores, V. do N. (org.). A redação no contexto do Vestibular 2005 - a avaliação em perspectiva. Porto Alegre: Editora UFRGS, 2005, pp. 37-57.

SILVA, E. M. \& LINO DE ARAÚJO, D. (2009). Redação no vestibular: efeito retroativo da noção de gêneros textuais. Trabalhos em Linguística Aplicada, v. 48, pp.133-152.

TOFFOLI, S. F. L. (2015). Avaliações em larga escala com itens de respostas construídas no contexto do Modelo Multifacetas de Rasch. Tese de Doutorado em Engenharia de Produção. Departamento de Engenharia de Produção e Sistemas, Universidade Federal de Santa Catarina, Florianópolis.

TFOUNI, L. V. A dispersão e a deriva na constituição da autoria e suas implicações para uma teoria do letramento. In: SIGNORINI, I. (org). Investigando a relação oral/escrito. Campinas: Mercado de Letras, 2001, pp. 77-94.

TFOUNI, L. V. (2008). Autoria: um lugar à espera? Estudos Linguísticos (São Paulo), v. 37, pp. $71-78$.

VAL, M. da G. C. Redação e Textualidade. São Paulo: Martins Fontes, 1991.

VIANNA, H. M. Comunicação e Expressão: problemas teóricos e práticos de avaliação. São Paulo: IBRASA, 1984.

VICENTINI, M. P. (2015). A redação no ENEM e a redação no $3^{\circ}$ ano do Ensino Médio: efeitos retroativos nas práticas de ensino da escrita. Dissertação de Mestrado em Linguística Aplicada. Instituto de Estudos da Linguagem, Unicamp, Campinas.

VIGNER, G. (1974) Técnicas de aprendizagem da argumentação escrita. In: GALVES, C.; ORLANDI, E. P.; OTONI, P. (orgs.) O texto: escrita e leitura. Campinas: Pontes, 1988, pp. 109-125. 
WIND, S. S. \& PETERSON, M. (2017). A systematic review of methods for evaluating rating quality in language assessment. Language Testing, v. 34, pp. 1-32.

Recebido: 8/04/2018

Aceito: 18/07/2018 